University of Nebraska - Lincoln

DigitalCommons@University of Nebraska - Lincoln

USDA National Wildlife Research Center - Staff Publications
U.S. Department of Agriculture: Animal and Plant Health Inspection Service

September 2007

\title{
Daytime cover, diet and space-use of golden jackals (Canis aureus) in agro-ecosystems of Bangladesh
}

\author{
Michael M. Jaeger \\ US Department of Agriculture, Animal and Plant Health Inspection Service, Wildlife Services, National \\ Wildlife Research Center \\ Emdadul Haque \\ Bangladesh Agriculture Research Institute (BARI) \\ Parvin Sultana \\ Bangladesh Agriculture Research Institute (BARI) \\ Richard L. Bruggers \\ US Department of Agriculture, Animal and Plant Health Inspection Service, Wildlife Services, National \\ Wildlife Research Center
}

Follow this and additional works at: https://digitalcommons.unl.edu/icwdm_usdanwrc

Part of the Environmental Sciences Commons

Jaeger, Michael M.; Haque, Emdadul; Sultana, Parvin; and Bruggers, Richard L., "Daytime cover, diet and space-use of golden jackals (Canis aureus) in agro-ecosystems of Bangladesh" (2007). USDA National Wildlife Research Center - Staff Publications. 701.

https://digitalcommons.unl.edu/icwdm_usdanwrc/701

This Article is brought to you for free and open access by the U.S. Department of Agriculture: Animal and Plant Health Inspection Service at DigitalCommons@University of Nebraska - Lincoln. It has been accepted for inclusion in USDA National Wildlife Research Center - Staff Publications by an authorized administrator of DigitalCommons@University of Nebraska - Lincoln. 


\section{Daytime cover, diet and space-use of golden jackals (Canis aureus) in agro-ecosystems of Bangladesh}

\author{
Michael M. Jaeger ${ }^{1, *}$, Emdadul Haque ${ }^{2}$, Parvin \\ Sultana $^{2}$ and Richard L. Bruggers ${ }^{3}$
}

1 US Department of Agriculture, Animal and Plant Health Inspection Service, Wildlife Services, National Wildlife Research Center, Utah State University, Logan, UT 84322, USA, e-mail: mjaeger@cc.usu.edu

2 Bangladesh Agriculture Research Institute (BARI), Vertebrate Pest Section, Joydebpur, Bangladesh

${ }^{3}$ US Department of Agriculture, Animal and Plant Health Inspection Service, Wildlife Services, National Wildlife Research Center, Fort Collins, CO 80521, USA

${ }^{*}$ Corresponding author

\begin{abstract}
Golden jackals are locally common in Bangladesh despite intensive cultivation and high human densities. We studied the relative importance of seasonal flooding, rodent prey-base, and daytime cover on the occurrence of golden jackals in the two major agro-ecosystems in Bangladesh, one with annual monsoon flooding and the other without. Jackals were less common throughout the year where floodwaters occurred that would have excluded them for 1-3 months during their pup-rearing season. Diets of jackals were similar in the two agro-ecosystems. Rodents were the most common food type in scats throughout the year. The occurrence of burrowing rats in scats peaked seasonally when these rats were most concentrated in ripening cereals, suggesting that jackals are beneficial for rat control. Radiotelemetry of seven jackals in the non-flooded agro-ecosystem over an 11-month period indicated that sugarcane was the preferred type of daytime cover, despite representing only $2-4 \%$ of the area. There was a day-to-day return rate of $67 \%$ to the same 1-ha patch of cover. Evidently, sugarcane provides daytime cover for avoiding humans and for feeding on roof rats (Rattus rattus), which concentrate in this crop. Evidence suggests that breeding pairs of jackals were annual residents that defended cover (average of $37.3 \mathrm{ha}$ ) but not foraging areas beyond.
\end{abstract}

Keywords: annual territories; daytime cover; rodent prey-base; seasonal flooding.

\section{Introduction}

The range of the golden jackal is extensive and includes contiguous areas of Africa, Asia, and Europe (Macdonald and Sillero-Zubiri 2004). This implies that the golden jackal is a habitat generalist, similar to the coyote (Canis latrans) in North America (Bekoff and Gese 2003). Both species are generalist predators with adaptable social systems (e.g., Macdonald 1979) that are able to exist in close proximity to humans and exploit agro-ecosystems. However, in some parts of their range, golden jackals have either disappeared or their numbers are shrinking due to anthropogenic causes (Jhala and Moehlman 2004). Surveys in Greece indicate that jackals have a fragmented distribution associated with coastal wetlands and that local populations are disappearing coincident with the destruction of the remaining patches of this habitat (Giannatos et al. 2005). Dense vegetation usually associated with wetlands may provide cover for avoiding humans during the daytime and be an important limiting factor for the existence of golden jackals in close proximity to humans. In contrast, golden jackals are reported to be expanding their range in Bulgaria (Krystufek et al. 1997). Conservation of this species depends on developing a better understanding of the resources that are necessary to sustain populations in agro-ecosystems.

Golden jackals occur in intensively cultivated areas of Bangladesh (Poché et al. 1987) despite an agrarian population density averaging more than 900 humans $/ \mathrm{km}^{2}$ (USAID 2006). In addition, extensive flooding occurs during the annual monsoon rains that would force jackals to vacate submerged areas for up to 3 months. Three resources seem necessary for jackals to become established under these conditions: (1) daytime cover, (2) a diet that is predominantly of rodents and does not seriously compete with humans for food (e.g., poultry and livestock), and (3) access to areas that do not flood annually for establishing territories and breeding. These resources are not mutually exclusive. For example, sugarcane has been suggested as an important source of both cover and food for jackals in cultivated areas of Pakistan (Khan and Beg 1986). In Bangladesh, jackals are relatively common in sugarcane-growing areas (Poché et al. 1987) but sugarcane is grown only where monsoon flooding is uncommon, suggesting that flooding per se, or its effect on the distribution of food, may be the more important determinant of jackal distribution. Flooding likely forces jackals and other carnivores to leave until after the waters recede. Breeding adults may not occur where they cannot be territorial throughout the year, as seems to be the case for the coyote (Shivik et al. 1996, Gantz and Knowlton 2005). Alternatively, flooding may impact the postflood density of burrowing rodents, particularly the lesser bandicoot rat (Bandicota bengalensis), which is common throughout south Asia. Golden jackals are reported to prey primarily upon rodents (Lanszki and Heltai 2002), including bandicoot rats (Khan and Beg 1986). Rodents are also an important prey for side-striped jackals (C. adustus; Atkinson et al. 2002). The importance of rodents in the annual diet is unknown for the agro-ecosystems of Bangladesh, where it is reported that jackals are primarily scavengers of human refuse (Poché et al. 1987). They also consume a variety of fruits and vegetables, 
together with poultry and livestock (Sarker and Ameen 1990). Farmers often respond to depredations by culling jackals.

The broad objective of this study was to determine the relative importance of annual access to territories, rodents in the diet, and availability of daytime cover to the occurrence of golden jackals in intensively cultivated areas of Bangladesh. Three specific questions were addressed: (1) do the two major agro-ecosystems (seasonally flooded versus not flooded) differ in relative abundance of jackals; (2) are rodents an important component of the annual diet; and (3) is daytime cover an important determinant of the distribution and local abundance of jackals.

\section{Materials and methods}

\section{Study sites}

Bangladesh is situated in the delta formed by the confluence of the Brahmaputra, Ganges, and Meghna Rivers. Extensive flooding occurs annually from June to October, coincident with the monsoon rains in south Asia. Flooding usually peaks by mid-August, when water covers one-third to half of the country. Most of this is due to run-off into the river systems from upstream in the Himalayas and not to the $2300 \mathrm{~mm}$ of average annual rainfall in Bangladesh itself (Ali 2002). Most rainfall (81\%) occurs during the monsoon season, with the remainder during the pre-monsoon summer season (March to May). The mean annual temperature in Bangladesh is $26^{\circ} \mathrm{C}$, it is coolest $\left(7-31^{\circ} \mathrm{C}\right)$ during the dry winter season (November to February) and warmest during summer $\left(30-40^{\circ} \mathrm{C}\right)$

There are two major agro-ecosystems based on the type of rice (Oryza sativa) grown in flooded (deep-water) versus non-flooded (paddy) areas. In both systems, rice is grown throughout the year in three seasons and wheat (Triticum aestivum) is grown in a single season (December to March). In addition, pulses (e.g., grass pea, Lathyrus sativus) and mustard (Brassica campestris) are common winter crops in both systems. Jute (Corchorus spp.) is grown in the seasonally flooded agro-ecosystem and sugarcane (Saccharum officinarum) in the non-flooded system. The study was conducted at two field sites: Mirzapur $\left(24^{\circ} 15^{\prime} \mathrm{N}, 8^{\circ} 55^{\prime} \mathrm{E}\right)$ representing the seasonally flooded (July-September) and Ishurdi $\left(24^{\circ} 08^{\prime} \mathrm{N}, 8^{\circ} 04^{\prime}\right.$ E) the non-flooded agro-ecosystem. The reader is referred to Sultana and Jaeger (1992) for a description of each agro-ecosystem, including the different crop types at each site, area cultivated with each, field sizes, and harvest periods. According to the 1991 census, Tangail District, which includes Mirzapur, had an overall population density of $910 / \mathrm{km}^{2}$ and Pabna District, which includes Ishurdi, an overall density of $850 / \mathrm{km}^{2}$ (www.citypopulation.de/Bangladesh.html). At Mirzapur, housing clusters become seasonal islands during the annual flood, and are surrounded by water of up to $6 \mathrm{~m}$ in depth and are accessible only by boat. A single allweather road serves this area. whereas at Ishurdi there is an intersection of two all-weather roads along which the study was conducted.
Jackals and jungle cats (Felis chaus) were observed at both sites, as were Bengal fox (Vulpes bengalensis), large Indian civets (Viverra zibetha), and mongoose (Herpestes spp.). In addition, a fishing cat (Prionailurus viverrinus) was captured at Ishurdi. A variety of rodents were common at both sites. Burrowing rats were concentrated in ripening cereals (Sultana and Jaeger 1992). The most common was the lesser bandicoot rat. The distribution of the greater bandicoot rat $(B$. indica) was more restricted to seasonally flooded areas at the Mirzapur site. The short-tailed mole rat (Nesokia indica) occurred only at the Ishurdi site (Poché et al. 1982). The roof rat (Rattus rattus) was common throughout the country but restricted to patches of dense vegetation (e.g., clusters of trees, vines, or sugarcane) in which it can climb and seek cover (Chandrasekar-Rao and Sunquist 1996). Domestic dogs occurred around clusters of houses, but were not encountered away from them.

\section{Sampling}

Field sites were sampled monthly from November 1986 to January 1988 for jackal scats to determine the relative density of jackals and the types of food they consumed. Vegetation type and field size were also recorded. In addition, the number of active burrow systems of bandicoot rats was sampled to determine whether the spatial or temporal distribution of this potentially important prey was likely to affect the occurrence or distribution of jackals. At each study site we established sampling areas by defining a $24-\mathrm{km}$ transect along the main roadway through the area and identifying $481-\mathrm{km}^{2}$ blocks, 24 along each side of the roadway. This approach was used because these general areas were inaccessible other than by foot. Each transect was partitioned into two equal strata of $12 \mathrm{~km}$ in length. For each of the first 6 months of the study, we randomly selected two $1-\mathrm{km}^{2}$ blocks in each stratum and within each block we randomly selected and sampled four 1-ha plots. In May 1987 , sampling was changed to the use of fixed blocks. This approach was used on the recommendation of a statistician for reasons to do with ANOVA and unrelated to the present study. Subsequently, we randomly selected four $1-\mathrm{km}^{2}$ blocks per stratum and then randomly selected two 1-ha plots from these same blocks each month. Under each sampling regime, we sampled 16 1-ha plots per site per month. Within each 1-ha plot, jackal scats were collected and their number recorded. The total number of scats collected per site per month was unlikely to be affected by the change in sampling procedure. The numbers of scats collected by this method were few; thus, for the purpose of diet analysis only, additional scats were collected opportunistically throughout the year at both sites.

We did not search through the vegetation within fields for scats so as to avoid damaging the crop. Instead, searches were along the bunds bordering each field. Fields were small at both Mirzapur and Ishurdi, averaging 0.12 and 0.19 ha, respectively (Sultana and Jaeger 1992). This resulted in a network of bunds and therefore a thorough search of 1-ha plots. 


\section{Diet analysis}

Food types consumed by jackals were determined by identifying undigested remains in their scats. A scat can consist of more than a single piece from the same dropping. Jackal scats were distinguished from those of other carnivores, including domestic dogs, foxes, civets, and jungle cats, by their characteristic size, shape, and contents. The reader is referred to Chame (2003) for a description of the scats of different carnivores. This process was carried out in the same way in which coyote scats are distinguished from those of bobcats (Lynx rufus), gray foxes (Urocyon cinereoargenteus), raccoons (Procyon lotor), striped skunks (Mephitis mephitis), and domestic dogs (Neale et al. 1998). Confusion was most likely to occur in distinguishing the scats of jackals from jungle cats owing to their similar dimensions and both tending to be straight in shape. Scats of these two species were distinguished from one another by well-defined segments characteristic of felids and by the presence of fruits, seeds, insect, plant tissue, etc. characteristic of the more omnivorous canids. In addition, scats of captive jackals and jungle cats that had been fed rats as part of another study to determine the number of rats consumed by an individual per day (R. Pandit unpublished data, BARI) were used as reference material. Nevertheless, some errors were likely in correctly assigning species of origin, but we assumed that this error was small. Jackals were observed more often than jungle cats, but the two species were captured in nearly equal numbers at the Ishurdi site where trapping occurred. Domestic dogs were uncommon and never encountered away from clusters of houses. Feral dogs and cats are not tolerated by Bangladeshi farmers.

In the laboratory, scats were boiled briefly in water and teased apart. The presence of hair, bone, feathers, exoskeleton, fish scales, plant material, etc. was recorded and identified when possible. Invertebrates found on the surface of scats were discarded. Rodent teeth and jaw parts were retained to identify species from unique cusp patterns of the molars (Peláez-Campomanes and Martin 2005) and to determine the minimum number of rodents/ scat.

\section{Radiotelemetry}

We captured 10 adult jackals at the non-flooded study site at Ishurdi between November 30, 1986 and March 15, 1987 using number 3 coil-spring, padded-jaw foothold traps. Traps were set after dark each evening, checked the next morning before dawn, and removed. Captured jackals were sedated with an intramuscular injection of ketamine hydrochloride $(10 \mathrm{mg} / \mathrm{kg}$ body mass) for approximately 20 min while their sex, age, and weight were determined and they were fitted with a radiocollar. Eyes were lubricated to protect against desiccation. The absence of tooth wear (Gier 1968) and body size were used to distinguish first-year from older jackals (i.e., juveniles from adults). Reproductive condition (e.g., lactation, descended testes) was also checked. Individuals were released at their trap site after regaining coordination, generally within $2 \mathrm{~h}$ of capture. There were no apparent injuries to any of the jackals from trapping or handling.

Radio tracking was carried out during 4-5 successive days each month. However, not all jackals could be located every day. Attempts were made to locate each jackal on at least 2 days/month. Tracking was done predominantly between dawn and dusk to obtain daytime locations in cover. Jackals were located with a hand-held Yagi antenna. At the onset of a radio-tracking session, it was determined whether the jackal was moving (fluctuating signal strength) or stationary (constant signal strength). The location and cover type of a stationary animal could be determined without triangulation using a single-antenna receiver. This was performed by following the general direction of the signal and when close to the animal circling to verify its position (1-ha plot). Triangulation of nighttime locations, when jackals were moving, could not be carried out with confidence. Interference from electrical power lines made it difficult to obtain accurate bearings (which are estimated by increasing and decreasing the gain on the receiver to hear subtle differences in signal strength) needed to triangulate positions. Nevertheless, the general direction and distance of the animal from the tracking position and whether or not it was moving could be determined.

\section{Results}

\section{Relative density of jackals}

A comparison of the number of jackal scats collected monthly at each study site is shown in Figure 1. Overall, more scats were found per month at Ishurdi than at Mirzapur (Mann-Whitney test, $\mathrm{U}_{0.05(2) 9,9}=64,0.01<\mathrm{p}<0.02$ ). There was an annual peak in the number of scats during March at both sites. This peak was greater at Ishurdi (Mann-Whitney test, $\mathrm{U}_{0.05(2) 16,16}=181,0.005<\mathrm{p}<0.01$ ). This represents the greatest monthly difference between sites in the number of scats found $(6.4: 1)$. This peak likely represents a seasonal change in the use of cultivated fields by jackals rather than a change in their density. The

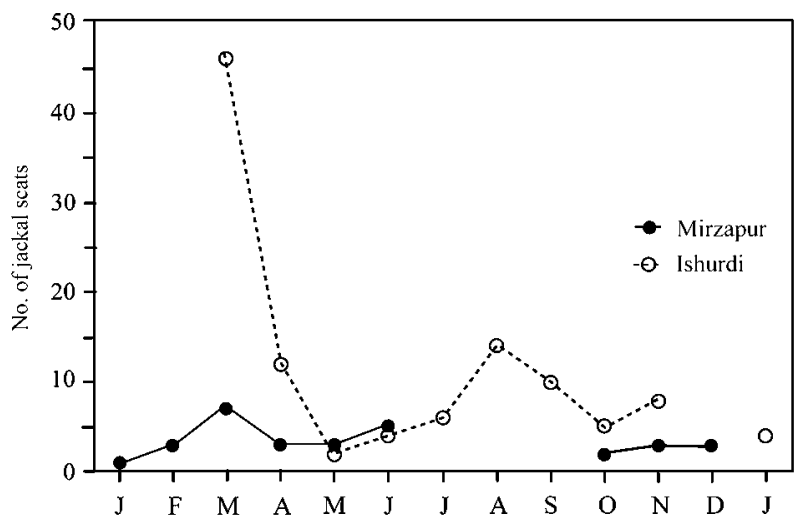

Figure 1 Monthly number of scats of golden jackals collected at each of the two study sites in Bangladesh during 1987. Dashed line represents the site at Ishurdi in the non-flooded agro-ecosystem and the solid line the site at Mirzapur in the seasonally flooded agro-ecosystem. The Mirzapur site was covered by floodwaters from July through August. 
Mirzapur site could not be sampled from July through September due to flooding. The entire area was under water ( $>1 \mathrm{~m}$ in depth) except for the man-made islands where humans were concentrated and the embankments of the major road through the area. Neither of these was sampled for scats.

\section{Jackal diet}

The trend in occurrence of different food items in scats was the same at both sites (Figure 2A). Rodents were the principal food type as measured by incidence of occurrence. Their bones and teeth were found in $62 \%$ of the 502 scats from Ishurdi and $56 \%$ of the 155 scats from Mirzapur. Birds were the second most common food type, occurring in $31 \%$ of the scats from both sites. Wild birds were not distinguished from domestic ducks and fowl. Plant material was found in $17 \%$ of the scats from
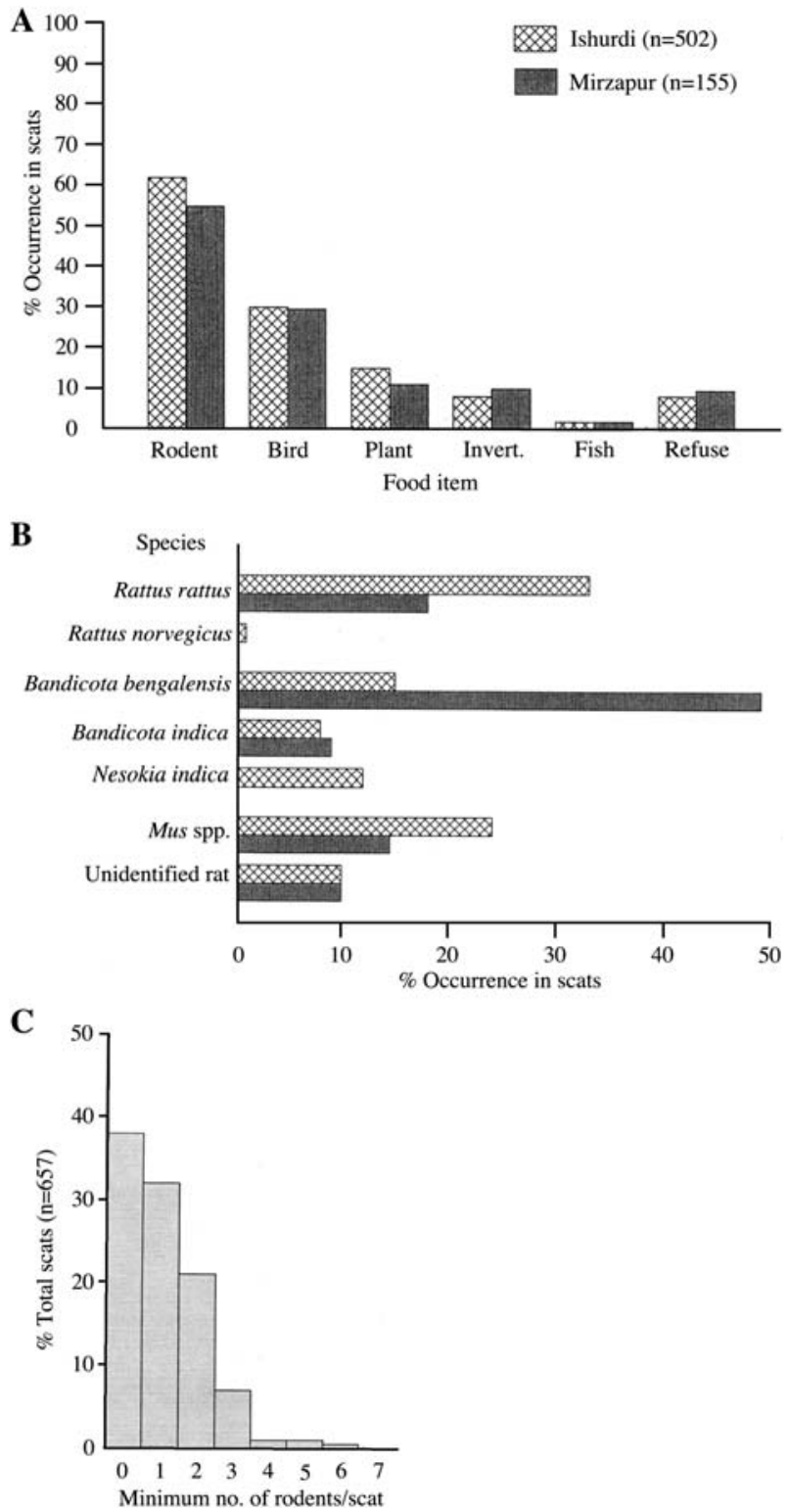

Figure 2 Importance of rodents in the diets of jackals from Ishurdi and Mirzapur during 1987: (A) incidence of different food types in scats; (B) incidence of rodent species in scats; and (C) minimum number of rodents/scat.
Ishurdi and $12 \%$ from Mirzapur. This was most often sugarcane stem or panicles of rice or wheat. Invertebrates, mostly insects, occurred in $9 \%$ and $10 \%$ of scats from Ishurdi and Mirzapur, respectively. Bones of livestock occurred in approximately $10 \%$ of the scats from each site and fish scales in $2 \%$.

The most common rodent remains were those of $R$. rattus, $B$. bengalensis, and Mus. spp., but the relative incidence of each varied between sites (Figure 2B). The incisors of two or more rodents were found in $30 \%$ of all scats, indicating a minimum average 1.1 rodents/scat (Figure 2C). All the scats from both sites, including those opportunistically collected $(n=606)$, were pooled to determine if there was an overall annual pattern in jackal predation on different rodent species. Pooling was carried out because there was no difference between sites in the relative incidence of different food types in scats and because no scats were collected from the Mirzapur site during monsoon flooding (July-September) and few were collected from October to December, thus making comparison between sites of little value. The proportion of burrowing rats (i.e., Bandicota spp. and $N$. indica) in scats decreased through the course of the year, being greatest from January through March and least from October through December (Figure 3). The proportion of scats with $R$. rattus and Mus spp. remained similar in all four quarters of the year. Independence between incidence of burrowing rats in scats (versus no burrowing rats) and season (January-June versus July-December) was rejected in a two-way analysis (G test, $\chi^{2}{ }_{(1)}=19.78$, $p<0.001)$, whereas it was accepted for both roof rats $\left(\chi^{2}{ }_{(1)}=0.06, \quad 0.9>p>0.5\right) \quad$ and mice $\left(\chi_{(1)}^{2}=0.62\right.$, $0.5>p>0.1)$. The decrease in incidence of burrowing rats was reflected in an increase in the incidence of refuse $\left(\chi^{2}{ }_{(1)}=20.64, p<0.001\right)$, a decrease in the incidence of birds $\left(\chi_{(1)}^{2}=5.58,0.025>p>0.01\right)$, and no change for either plant material $\left(\chi_{(1)}^{2}=2.68,0.5>p>0.1\right)$ or invertebrates $\left(\chi_{(1)}^{2}=0.02,0.9>p>0.5\right)$.

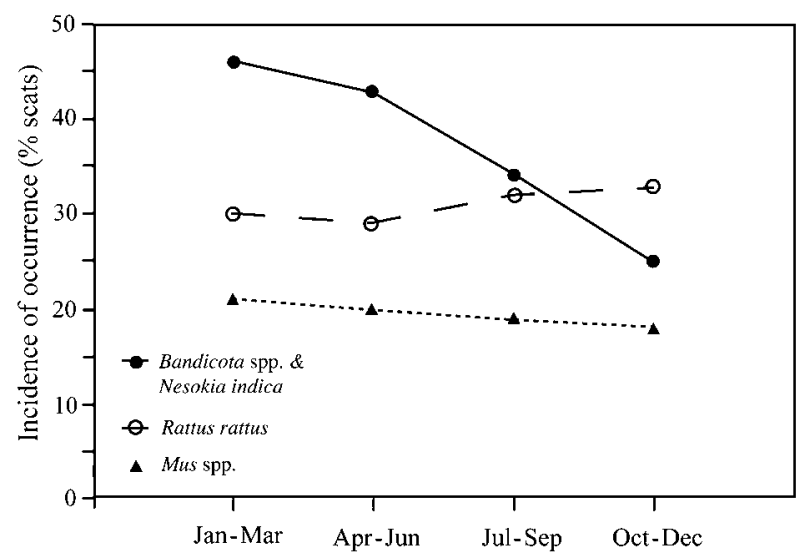

Figure 3 Seasonal trend in the occurrence of burrowing rats, roof rats, and mice in the scats of golden jackals in Bangladesh during 1987-1988. Scats from the two study sites are pooled. Sample sizes are as follows: $n=212$ scats for January-March, $\mathrm{n}=89$ for April-June, $\mathrm{n}=107$ for July-September, and $\mathrm{n}=198$ for October-December. 


\section{Daytime cover}

Radio tracking of seven jackals over periods ranging from 5 to 11 months indicated that they used cover throughout the hours of daylight. Between 07:00 and 17:00 h, $97 \%$ of locations $(n=86)$ were in cover, compared with $72 \%$ of locations $(n=18)$ from $05: 00$ to $07: 00 \mathrm{~h}$ and $73 \%$ of locations $(n=49)$ from 17:00 to 19:00 h. Sugarcane was the preferred type of cover. All jackals used it when it was available. The 44 locations during DecemberFebruary were all in sugarcane, compared to 38 of 51 locations during March-May (G-test, d.f. $=2, p<0.005$ ). This difference may have been due to the staggered harvest among sugarcane fields, which began in December and was completed by April. This resulted in a staggered re-growth of the ratoon sugarcane. From December to January, $85 \%$ of cover used was mature sugarcane, with the remainder being the emerging ratoon crop. By April-May, only $11 \%$ of the cover used was mature sugarcane and $56 \%$ was emerging sugarcane. The availability of sugarcane at Ishurdi varied seasonally between $2 \%$ and $4 \%$ of the area sampled. Use of alternative cover ( $n=13$ locations) was equally divided among bamboo, jute, and ripening rice and wheat. The likelihood that daytime cover was limited in availability is suggested by the high incidence of reuse of the same 1-ha patch of cover on successive days by the same jackal ( $67 \%$ return rate). Reuse of the same 1-ha patches in successive months occurred $34 \%$ of the time. The Ishurdi site was intensively cultivated throughout the year, with a monthly average of $74.8 \%$ of the area sampled covered by crops, $15.8 \%$ plowed or fallow, and $9.4 \%$ uncultivated.

The spatial and temporal patterns of stationary daytime locations of seven jackals monitored over 11 months (December-October) are shown in Figures 4 and 5. Daytime cover used by five of the animals ( 01 , $\$ 3$, +5 , $q 6$, and $q 8$ ) was clumped in relatively small areas that tended not to overlap among individuals. This indicates that these jackals were resident in the same exclusive (i.e., defended) areas throughout the year. There were two exceptions. First, o 2 moved from his original area of daytime cover to an area of sugarcane approximately $3 \mathrm{~km}$ away (Figure 5A,B) after his mate ( $\$ 10)$ and their pups were killed by farmers. This occurred in April following discovery of their den in a wheat field during harvest. This jackal ( $₫ 2)$ was itself killed by farmers in August. Prior to moving, this jackal's use of daytime cover partially overlapped that of $\delta 1$. On two occasions, these males were located traveling together at night, suggesting that $\delta 2$ may have been a beta male residing in its natal territory. Second, $\delta 7$ was a 1-2-year-old non-resident transient (i.e., dispersed from his natal territory) who was located only once after March (Figure 5E). Evidently this jackal was forced to disperse following harvest of the sugarcane it had been sharing with $q 6$ and at least one other unidentified jackal.

The size of each territory as determined by daytime locations in cover was affected not only by the presence of conspecifics in contiguous territories, but also by the spatial and temporal distribution of sugarcane or other suitable cover. The area of daytime cover used by each jackal was calculated (as illustrated in Figure 5F) by total-

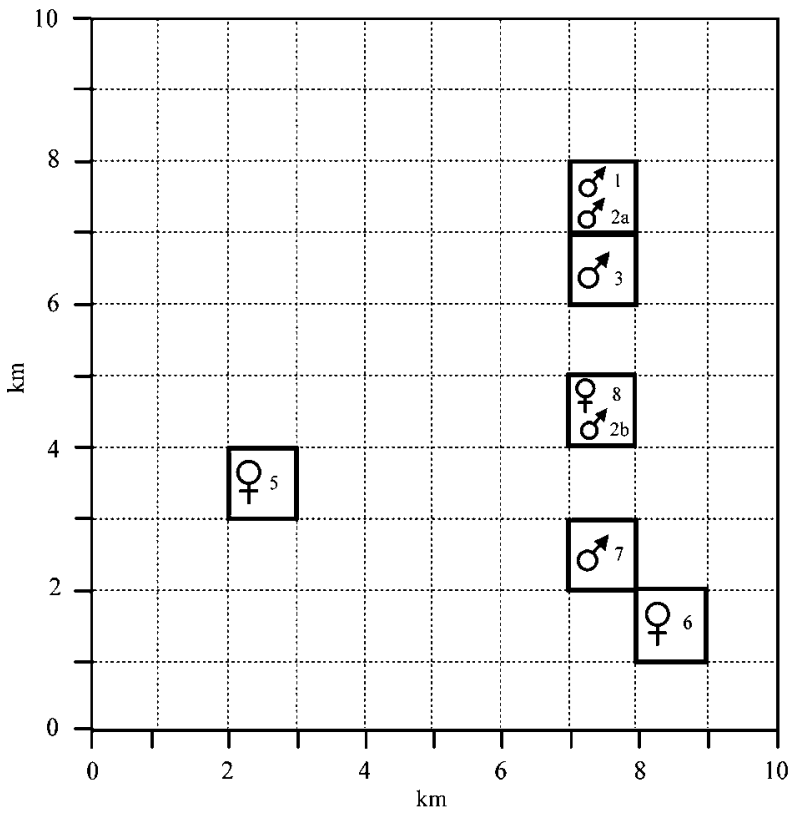

Figure 4 Map illustrating the relative areas of daytime cover used by each of the seven golden jackals that were tracked using radiotelemetry. Areas are presented in the form of grid squares $\left(1 \mathrm{~km}^{2}\right)$, which refer to each jackal's respective reference square in Figure 5.

ing the minimum number of contiguous 1-ha plots that encompassed all plots used by an individual for cover. These averaged $57.3( \pm 43.3, \pm 1 \mathrm{SD})$ ha for the six resident jackals (area used for $\delta 2$ was the 5-month period after moving). Female 6 also moved her area of daytime cover following the harvest of sugarcane (Figure 5G). If only the area used after this move is considered (May-October) the average area for the six jackals becomes 37.3 ( \pm 23.4$)$ ha. Telemetry indicated that jackals departed from cover at dusk and returned again at dawn and that their movements were outside of the territories defined by cover. Precise locations of moving jackals could not be determined.

\section{Discussion}

\section{Jackal density}

The scat index indicates an overall difference in jackal density between the two major agro-ecosystems. One or more of the following factors may affect this difference: seasonal flooding, prey base, and daytime cover. The spike in the number of scats found in cultivated fields in March coincided with the time of year when lesser bandicoot rats were most concentrated. We found an average of $57 \mathrm{rats} / \mathrm{ha}$ in ripening wheat at Mirzapur, double that at Ishurdi (Sultana and Jaeger 1992). This difference may have been due to greater predation by jackals (and jungle cats) at Ishurdi. At both sites, over $90 \%$ of rat burrows were in wheat fields, which represented approximately $11 \%$ of the area cultivated in each agroecosystem (Sultana and Jaeger 1992). This indicates that jackals focused their foraging where these rats were concentrated. This is supported by the finding that the incidence of bandicoot rats in scats was highest at this time 
A
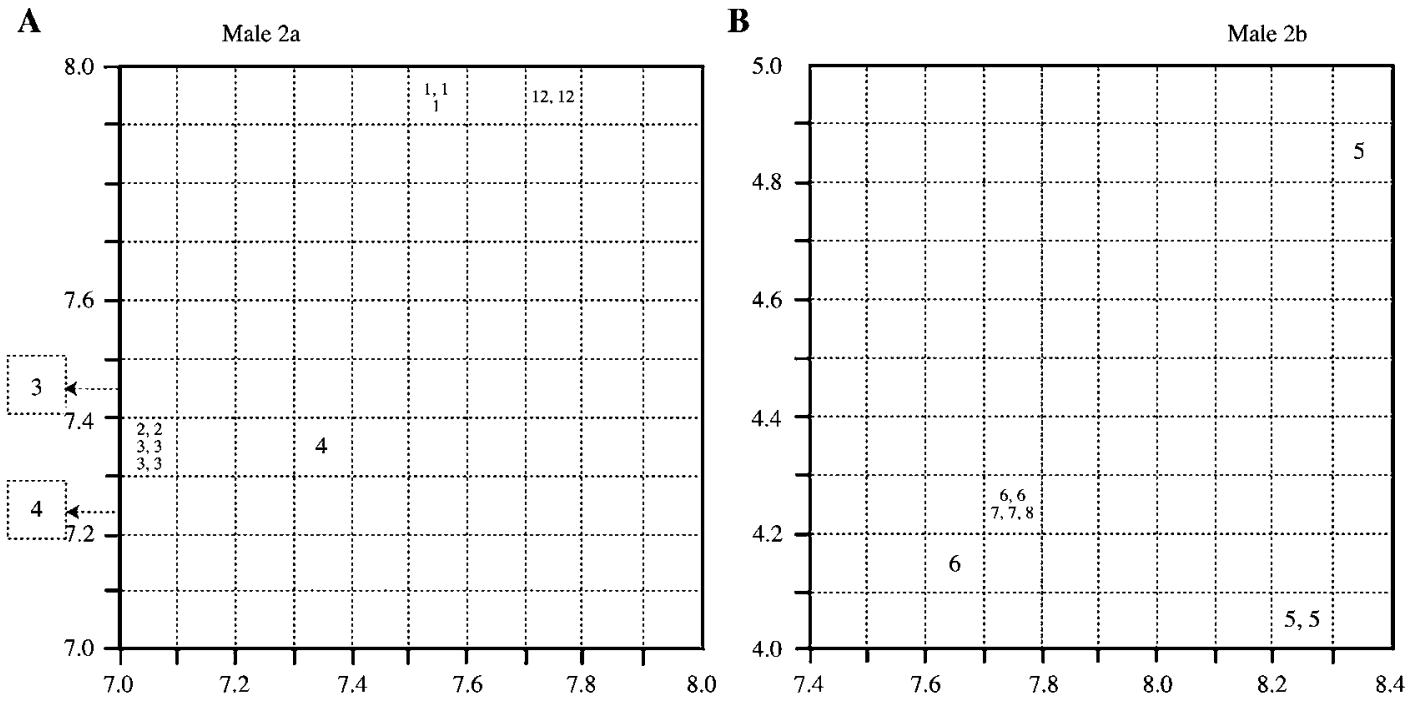

C

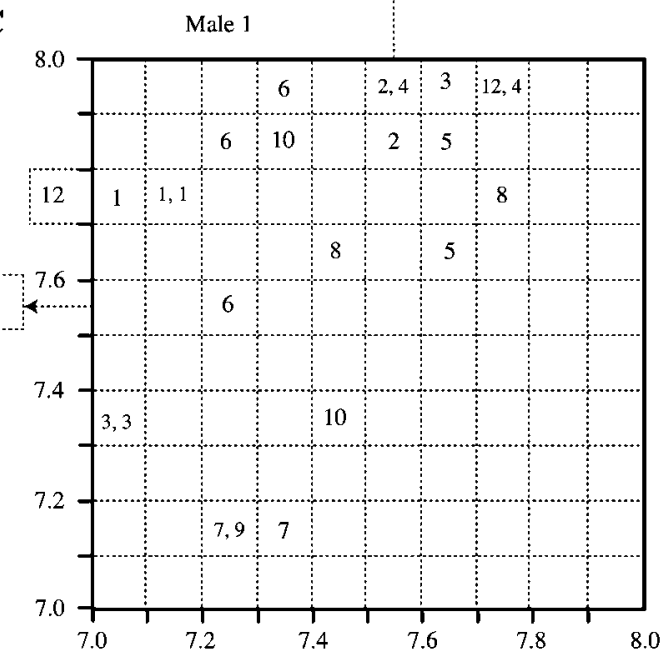

E

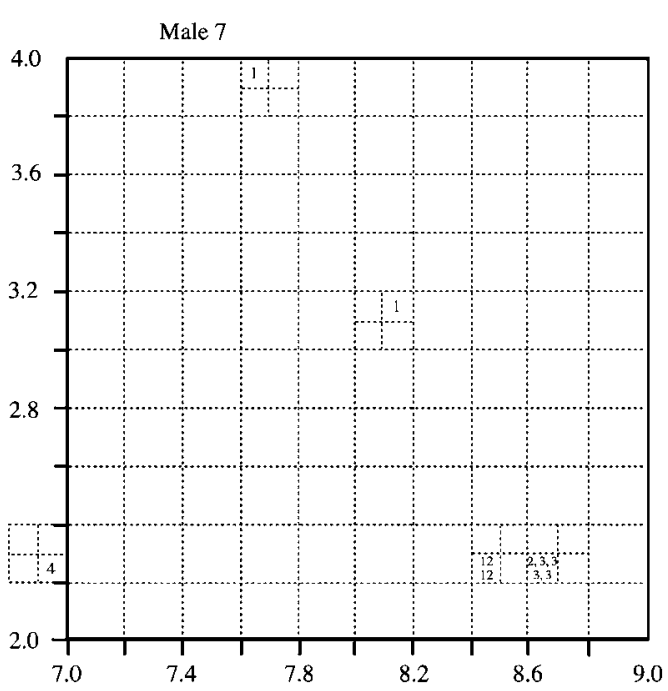

D

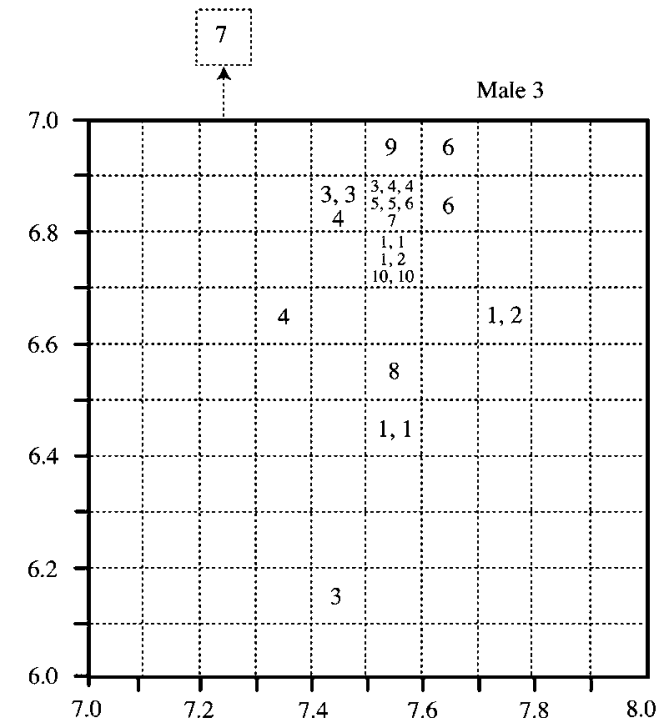

F

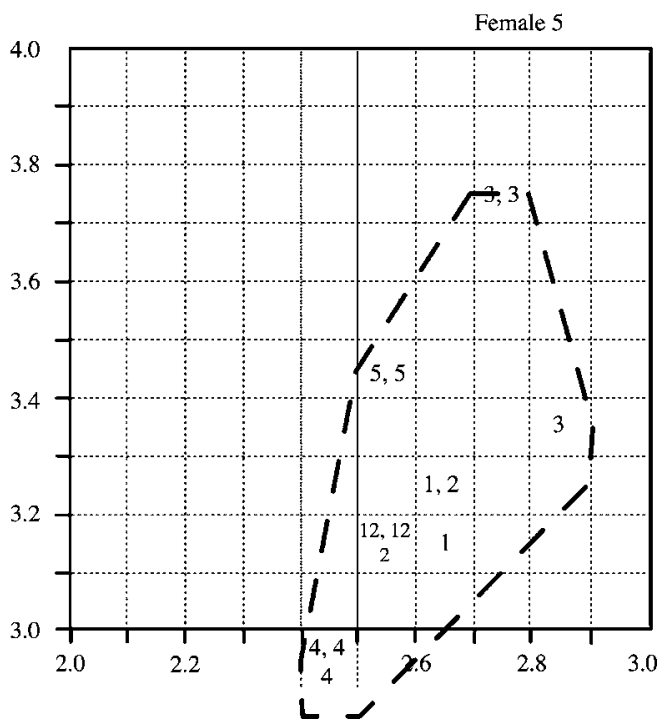


(Figure 5 continued)

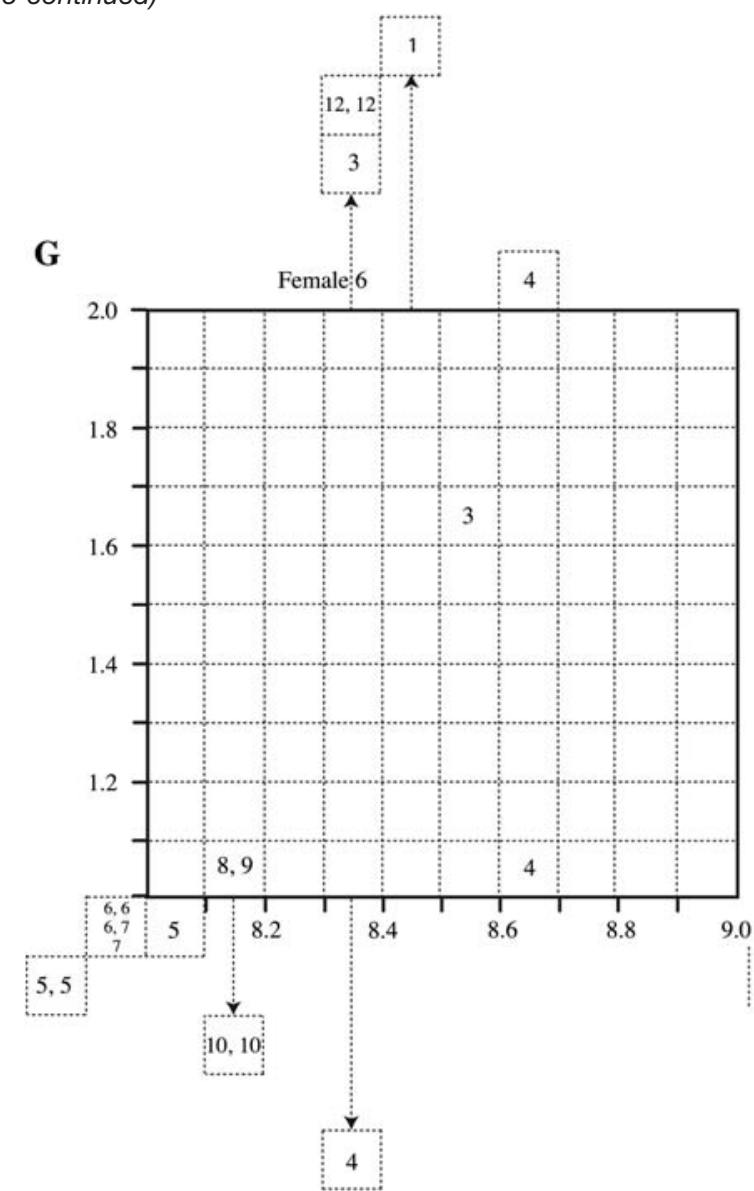

$\mathbf{H}$

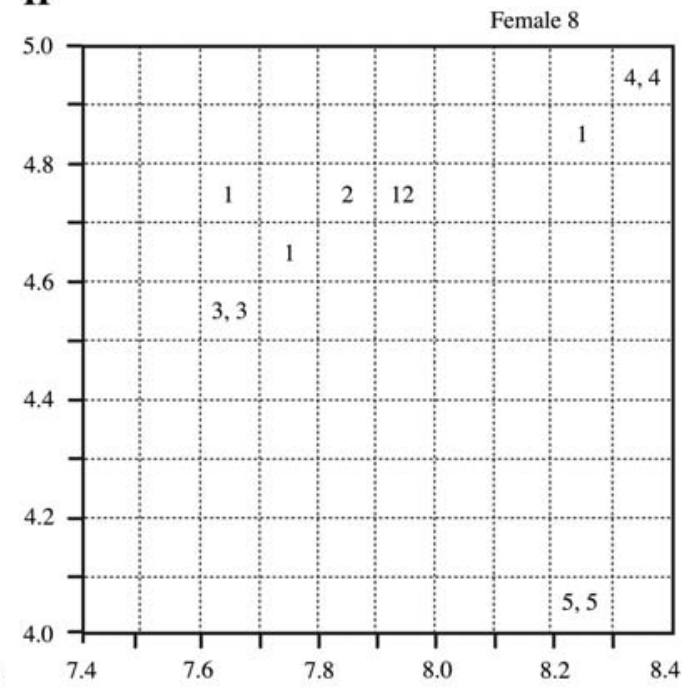

Figure 5 Maps showing 1-ha locations of each jackal in daytime cover during the period from December 1986 to October 1987. Numbers in grid squares represent the month (1-12) during which a location was made in that 1-ha square. There is one location per day and up to five successive daily locations in a month. The map for female 5 (F) illustrates how the area of daytime cover for each golden jackal is determined. All grid squares within the boundaries and through which the boundary line passes are counted. In this example the area encompassing daytime cover is 35 ha.

of year (Figure 3). The extent of the difference in jackal density between agro-ecosystems is probably best reflected by the numbers of scats found during March. At other times of year, relatively few scats were found in cultivated fields at either site. This maybe because jackals did not deposit scats randomly, but used them for advertising their claim to a limited resource such as territory space (Macdonald 1979) or a wheat field and its rats. This is elaborated on in the section dealing with diet.

\section{Seasonal flooding}

The scat index indicates that jackals were less abundant where seasonal flooding occurred. This is not surprising during the monsoon season, but the difference persisted throughout the year. Flooding was extensive in the deepwater rice agro-ecosystem represented by Mirzapur. Most of this study area was flooded to a depth of 1-3 m from July through September. Deep-water rice is grown during the floods, which is the crop type that distinguishes this agro-ecosystem. It seems reasonable that extensive flooding adversely affects the abundance of jackals by excluding them from areas with deep water. It is unknown whether some jackals remain on small patches of high ground throughout the floods or whether they tend to migrate back and forth into these areas with the rising and receding flood waters. However, it seems likely that breeding jackals, similar to breeding (i.e., alpha) coyotes, do not establish territories where they cannot maintain them year round (Shivik et al. 1996, Gantz and Knowlton 2005), particularly during pup rearing. Whelping of pups peaks in March and the young are unlikely to become independent before August-September when floodwaters are present. Consequently, it is the transient non-breeding jackals that seem more likely to use flooded areas on a seasonal basis.

\section{Prey base}

Bandicoot rats, roof rats, and mice were the most common prey in the scats of jackals from both agro-ecosystems. The importance of rodents in the diets of jackals is consistent with findings from elsewhere on the subcontinent (Khan and Beg 1986, Mukherjee et al. 2004). Bandicoot rats are the most common rat in cultivated cereals and pulses throughout Bangladesh. Through the use of underground burrow systems (Poché et al. 1982) they are able to exist in cultivated areas where vegetative cover provided by crops is insufficient protection from predators. Each adult establishes a separate burrow system in which it caches ripening panicles, allowing it to remain underground for extended periods (Sultana and 
Jaeger 1992). Results from a concurrent study (Sultana and Jaeger 1992) found a similar annual cycle in the overall density of active burrows (i.e., adults) at both study sites, with the peak (15-20 burrows/ha) in November and December coincident with the main (aman) rice harvest and a low ( $<1$ burrow/ha) from July to September during the monsoon. Secondary and tertiary peaks coincided with the wheat (March) and boro rice (May-June) harvests, respectively. Bandicoot burrows were most concentrated in wheat and boro rice owing to the relatively small areas cultivated. Interestingly, it was at these times that the incidence of bandicoot rats in scats was greatest (Figure 3). Incidence was lowest during October-December, when rats were dispersed in aman rice that covered approximately $60 \%$ of the cultivated land in both agro-ecosystems. At Ishurdi (non-flooded), bandicoot rats remained important in the diet of jackals during the monsoon, despite their overall low density. Evidently, jackals found concentrations of burrows on well-drained road embankments or in and around structures with stored grain (M.Y. Mian, unpublished data, BARI).

There was no seasonal change in the numbers of roof rats or mice in scats. Roof rats, like lesser bandicoot rats, were common at both sites (Mian et al. 1987). Unlike lesser bandicoot rats, roof rats are restricted to structures or vegetation on which they can climb and build nests above ground; sugarcane fields provide suitable habitat where roof rats will concentrate. At Ishurdi, jackals used sugarcane for daytime cover; and evidently fed on the roof rats that were common in these fields. Sugarcane was present through the monsoon and in the months that followed when the consumption of bandicoot rats was relatively low. Sugarcane therefore provided both cover and a daytime food source for jackals. The lower incidence of roof rats in scats at Mirzapur (Figure 2B) may be due in part to the absence of sugarcane, but also to a sampling bias at this site, in that more scats were collected at the time of year when the incidence of bandicoot rats in scats was highest (i.e., February-March).

Evidence indicates that jackals did scavenge anthropogenic refuse at both sites, but that this was not their primary food source in either agro-ecosystem. However, the incidence of refuse in scats increased seasonally when that of burrowing rats decreased (July-December), suggesting that refuse was used to supplement the loss of these rats. Refuse may be an even more important food source in other situations within Bangladesh where the abundance of rodents is less (Poché et al. 1987), as has been reported in Israel (Macdonald 1979, Yom-Tov et al. 1995). The implication is that rats are the preferred food source where they are available. Similarly, urban coyotes have been reported to prey primarily on small mammals (Morey et al. 2007).

A high incidence of bird remains was found in scats from both sites. The proportion corresponding to domestic fowl was not determined. However, the decrease in the incidence of birds in scats during the monsoon suggests that jackals had been feeding primarily upon wild granivorous birds that would have departed at this time of year when grain was scarce. The most likely source of wild birds would have been from their night roost sites. Flocks of wild birds commonly roosted in sugarcane and those that died of natural causes during the night may have been scavenged by jackals. A similar reduction in the incidence of birds in scats during the monsoon was reported by Sarker and Ameen (1990). They reported that most bird remains from an urban study site in Bangladesh were those of domestic chickens and ducks.

It is unclear from our data whether jackals killed livestock to provision pups as coyotes do (Till and Knowlton 1983). Depredation seems most likely during the monsoon because of increased energetic needs, together with the reduced availability of bandicoot rats. Black Bengal goats (a dwarf variety) were the most likely type of livestock to have been preyed upon by jackals owing to their relative abundance and small size. However, there was no evidence of goat hair in scats. Jackals do kill these goats (personal observation) and the remains of goats have been found in scats from Bangladesh (Sarker and Ameen 1990), but this is not reported to be an important constraint to goat production. This may be because flock sizes were small and as a consequence the goats are easy to pen at night near humans.

\section{Daytime cover}

Radio-collared jackals at Ishurdi used cover during daylight hours and were rarely located in the open during the day. This finding is consistent with the behavior of golden jackals in Ethiopia (Admasu et al. 2004), Greece (Giannatos et al. 2005) and with coyotes in areas where they are exploited by humans, particularly in connection with livestock depredation (Sacks 1996, Kitchen et al. 2000). On several occasions jackals were observed to be pursued by a group of children after having been flushed from daytime cover. Three of the 11 jackals captured at Ishurdi were known to have been killed by farmers. For jackals to exist where human density is high requires effective avoidance of detection during daylight and the use of cover of darkness for activity in the open. Red fox (Vulpes vulpes) in Europe (Lucherini et al. 1995) and coyotes in North America (Grinder and Krausman 2001) are also able to live in close association with humans, including in urban areas. Where golden jackals are not threatened by humans, they are more diurnal in their activity (Fuller et al. 1989).

Sugarcane was the favored type of daytime cover at Ishurdi, despite there being relatively little of it. Sugarcane is typically grown in small holdings ( $<1 \mathrm{ha}$ ). In some areas of Bangladesh, sugarcane fields are much more numerous and it is in these areas that jackal densities are relatively high (Jaeger et al. 1996). This observation is supported by surveys in Greece that showed golden jackals to be restricted to patches of dense marsh along the coast (Giannatos et al. 2005). High stalk density and extensive lodging of stalks make a mature sugarcane field virtually impenetrable to humans. In addition, the availability of roof rats, roosting birds, and sugarcane stalks (that jackals are fond of chewing on) provide food that was utilized during the day. Other species of carnivores were trapped on the edges of sugarcane fields at Ishurdi, suggesting that they also use sugarcane for daytime cover. These included the jungle cat, fishing cat, mongoose, and small Indian civet. Jungle cats were 
relatively common at Ishurdi; nine were captured in the process of trapping 11 jackals.

\section{Annual territoriality}

We have suggested that access to territoriality throughout the year, a prey-base that is not competed for with humans (i.e., rodents), and suitable daytime cover are all necessary conditions for jackals to maintain stable populations in densely populated agro-ecosystems. A distribution of suitable cover that is patchy in both space and time, such as was found with sugarcane at Ishurdi, can potentially disrupt year-around territoriality. Evidence from Ishurdi (including Poché et al. 1987) suggests most jackals were resident throughout the year and that their nighttime home ranges probably overlapped, while areas used for daytime cover were more exclusive (e.g., males 1 and 3 , Figures 4 and $5 C, D$ ). This implies that breeding pairs of jackals defended areas of cover (with roof rats), but not foraging areas beyond (i.e., fields with bandicoot rats). This is a departure from the more common situation in canids such as the coyote where the breeding pair defends a territory that includes all necessary resources (i.e., home range and territory are the same, e.g., Andelt (1985). Macdonald (1979) showed that the expression of territoriality in golden jackals can be flexible and dependent on the distribution of resources.

The average size of putative territories at Ishurdi (as determined by the spatial pattern of daytime cover) was only 37 ha. This compares with approximately 200 ha for a resident pair of golden jackals in a Kenya study (Fuller et al. 1989) and home ranges of 39 ha and 173 ha for two resident females reported from Algeria (Khidas 1990). A home range size ranging from 1.1 to $20.0 \mathrm{~km}^{2}$ is reported for this species by Macdonald and Sillero-Zubiri (2004). The overall area used for daytime cover by individual jackals at Ishurdi is a cumulative area over months and does not reflect the day-to-day use of cover. Resident jackals often returned to the same 1-ha patch of sugarcane on successive nights and even across successive months (Figure 5D) which would be expected when pups were in dens.

\section{Implications for conservation and management}

The results of this study indicate that both annual access to an area and suitable cover are important factors influencing local abundance of golden jackals in the major agro-ecosystems of Bangladesh. The potential exists to manipulate cover (e.g., sugarcane) for the conservation and management of golden jackals, jungle cats, and other medium and small carnivores. A scattered distribution of sugarcane is likely to increase opportunities to establish territories (maximum density of approx. 1 territory/ $\mathrm{km}^{2}$ ), while its staggered harvest in the same area (i.e., $\leq 1 \mathrm{~km}^{2}$ ) is likely to provide year-around cover within the same territory. Clustering territories so that they can be contiguous may be important to success (e.g., groups of 2-4 territories). Conservation of jackals assumes the cooperation of farmers. This may be possible where jackals are not dependent on anthropogenic sources of food, particularly poultry and livestock, and where their prey base has pest status. In agricultural areas of Bangladesh, as elsewhere on the Indian sub-continent, jackals prey primarily upon rodents and as a consequence are probably beneficial for rat control, particularly in pre-harvest cereals and sugarcane. This is supported by the greater density of bandicoot burrows in mature wheat (March) at the study site, with fewer jackals: 53.8 \pm 10.7 ( \pm SE) burrows/ha at Mirzapur (seasonal flooding) versus $21.9 \pm 4.4$ burrows/ha at Ishurdi (no flooding). The relative area cultivated in wheat was similar at the two sites: $11.5 \%$ and $10.9 \%$, respectively.

\section{Acknowledgements}

We thank F. Knowlton for comments on the manuscript and assistance with the figures. Two anonymous reviewers made substantial improvements to the manuscript. Funding was provided by USAID under the project "Agricultural Research II Vertebrate Pest Management Component, PASA IBD-0051-P-IF2252-05". Use of animals in this research complies with the current laws of Bangladesh.

\section{References}

Admasu, E., S.J. Thirgood, A. Bekele and M.K. Laurenson. 2004. Spatial ecology of golden jackal in farmland in the Ethiopian Highlands. Afr. J. Ecol. 42: 144-152.

Ali, M.L. 2002. An integrated approach for improvement of flood control and drainage schemes in the coastal belt of Bangladesh. Taylor Francis, London. pp. 24-25.

Andelt, W.F. 1985. Behavioral ecology of coyotes in south Texas. Wildl. Monogr. 94: 1-45.

Atkinson, R.P.D., D.W. Macdonald and R. Kamizola. 2002. Dietary opportunism in side-striped jackals Canis adustus Sundevall. J. Zool. Lond. 257: 129-139.

Bekoff, M. and E.M. Gese. 2003. Coyote (Canis latrans). In: (G.A. Feldhamer, B.C. Thompson and J.A. Chapman, eds.) Wild mammals of North America: biology, management, and conservation. Johns Hopkins University Press, Baltimore, MD. pp. 467-481.

Chame, M. 2003. Terrestrial mammal feces: a morphometric summary and description. Mem. Inst. Oswaldo Cruz, Rio de Janeiro 98 (Suppl. 1): 71-94.

Chandrasekar-Rao, A. and M.E. Sunquist. 1996. Ecology of small mammals in tropical forest habitats of southern India. J. Trop. Ecol. 12: 561-571.

Fuller, T.K., A.R. Biknevicius, P.W. Kat, B. Van Valkenburgh and R.K. Wayne. 1989. The ecology of three sympatric jackal species in the Rift Valley of Kenya. Afr. J. Ecol. 27: 313-323.

Gantz, G.F. and F.F. Knowlton. 2005. Seasonal activity areas of coyotes in the Bear River Mountains of Utah and Idaho. J. Wildl. Manage. 69: 1652-1659.

Giannatos, G., Y. Marinos, P. Maragou and G. Catsadorakis. 2005. The status of the golden jackal (Canis aureus L.) in Greece. Belg. J. Zool. 134: 37-42.

Gier, H.T. 1968. Coyotes in Kansas (revised). Kans. State Coll. Agric. Exp. Sta. Bull. 393: 1-118.

Grinder, M.I. and P.R. Krausman. 2001. Home range, habitat use, and nocturnal activity of coyotes in an urban environment. J. Wildl. Manage. 65: 887-898.

Jaeger, M.M., R.K. Pandit and E. Haque. 1996. Season differences in territorial behavior by golden jackals in Bangladesh: howling versus confrontation. J. Mammal. 77: 768-775.

Jhala, Y.V. and P.D. Moehlman. 2004. Golden jackal (Canus aureus). In: (C. Sillero-Zubiri, M. Hoffmann and D.W. Macdonald eds.) Canids: foxes, wolves, jackals and dogs. Status survey and conservation action plan. IUCN/SSC Canid Spe- 
cialist Group, Gland, Switzerland, and Cambridge, UK. pp. 156-161.

Khan, A.A. and M.A. Beg. 1986. Food of some mammalian predators in the cultivated areas of Punjab. Pak. J. Zool. 18: 71-79.

Khidas, K. 1990. Contribution à la connaissance du chacal doré. Facteurs modulant l'organisation sociale et territoriale de la sous-espèce algérienne (Canis aureus algirensis Wagner, 1941). Mammalia 54: 363-375.

Kitchen, A.M., E.M. Gese and E.R. Schauster. 2000. Changes in coyote activity patterns due to reduced exposure to human persecution. Can. J. Zool. 78: 855-857.

Krystufek, B., D. Murariu and C. Kurtonur. 1997. Present distribution of the golden jackal Canis aureus in the Balkans and adjacent regions. Mamm. Rev. 27: 109-114.

Lanszki, J. and M. Heltai. 2002. Feeding habits of golden jackal and red fox in south-western Hungary during winter and spring. Mamm. Biol. 67: 129-136.

Lucherini, M., S. Lovari and G. Crema. 1995. Habitat use and ranging behaviour of the red fox (Vulpes vulpes) in a Mediterranean rural area: is shelter availability a key factor? J. Zool. Lond. 237: 577-591.

Macdonald, D.W. 1979. The flexible social system of the golden jackal, Canis aureus. Behav. Ecol. Sociobiol. 5: 17-38.

Macdonald, D.W. and C. Sillero-Zubiri. 2004. Dramatis personae. In: (D.W. Macdonald and C. Sillero-Zubiri eds.) Biology and conservation of wild canids. Oxford University Press, Oxford. pp. 3-36.

Mian, M.Y., M.S. Ahmed and J.E. Brooks. 1987. Small mammals and stored food losses in farm households in Bangladesh. Crop Prot. 6: 200-203.

Mukherjee, S., S.P. Goyal, A.J.T. Johnsingh and M.R.P. Leite Pitman. 2004. The importance of rodents in the diet of jungle cat (Felis chaus), caracal (Caracal caracal) and golden jackal (Canis aureus) in Sariska Tiger Reserve, Rajasthan, India. J. Zool. Lond. 262: 405-411.
Morey, P.S., E.M. Gese and S. Gehrt. 2007. Spatial and temporal variation in the diet of coyotes in the Chicago Metropolitan Area. Am. Midl. Nat. in press

Neale, J.C.C., B.N. Sacks, M.M. Jaeger and D.R. McCullough 1998. A comparison of bobcat and coyote predation on lambs in north-coastal California. J. Wildl. Manage. 62: 700706.

Peláez-Campomanes, P. and R.A. Martin. 2005. The Pliocene and Pleistocene history of cotton rats in the Meade Basin of southwestern Kansas. J. Mammal. 86: 475-494.

Poché, R.M., M.Y. Mian, M.E. Haque and P. Sultana. 1982. Rodent damage and burrowing characteristics in Bangladesh wheat fields. J. Wildl. Manage. 46: 139-147.

Poché, R.M., S.J. Evans, P. Sultana, M.E. Haque, R. Sterner and M.A. Siddique. 1987. Notes on the golden jackal (Canis aureus) in Bangladesh. Mammalia 51: 259-270.

Sacks, B.N. 1996. Ecology and behavior of coyotes on a California sheep ranch in relation to depredation and control. MS thesis, University of California, Berkeley.

Sarker, N.J. and M.N. Ameen. 1990. Food habits of jackals (Canis aureus). Bangladesh J. Zool. 18: 189-202.

Shivik, J.A., M.M. Jaeger and R.H. Barrett. 1996. Coyote movements in relation to the spatial distribution of sheep. J. Wildl. Manage. 60: 422-430.

Sultana, P. and M.M. Jaeger. 1992. Control strategies to reduce rat damage in Bangladesh. In: (J.E. Borrecco and R.E. Marsh, eds.) Proceedings of the 15th Vertebrate Pest Conference, University of California, Davis. pp. 261-267.

Till, J.A. and F.F. Knowlton. 1983. Efficacy of denning in alleviating coyote depredations upon domestic sheep. J. Wildl. Manage. 47: 1018-1025.

USAID. 2006. http://www.usaid.gov/bd/pop.html

Yom-Tov, Y., S. Ashkenazi and O. Viner. 1995. Cattle predation by the golden jackal Canis aureus in the Golan Heights, Israel. Biol. Cons. 73: 19-22. 